\title{
HOW COVID-19 HAVE ENFORCED SOCIAL INEQUALITIES - EXPERIENCE OF ESTONIAN TEACHERS
}

\author{
Karmen Trasberg \\ University of Tartu, Estonia
}

\begin{abstract}
Students across the world have missed face-to-face instruction due to COVID-19 for many months. While schools have made valiant efforts to continue the provision of learning for students, the success of those efforts has varied, and has often been hindered by limited access to technologies and high-speed broadband available in the homes of teachers and students. The changes have enforced existing social inequalities because of insufficient skills, resources, time or health to assist children with remote learning. Closing schools disrupted the education of all children, but some will have coped better than others. Children are differentially advantaged, reflecting their background and circumstances.

The aim of this article is to explore how Estonian teachers have experienced the teaching and learning remotely during the first lockdown period in 2020 and what are the possible consequences for vulnerable student' groups.

The paper draws on a qualitative method study based on recent interviews with teachers $(n=20)$ in ten schools. It turned out from the study that there are positive attitudes towards using digital tools in the learning process, but it has not clear impact on the development of digital skills. The results indicated that there is a fragmentation and wide variety of approaches practiced in Estonian general education schools and not all students benefited from the best practices of distance learning. One of the main threats to students with special educational needs (SEN) was the interruption of their study routine, including support services and creating a new daily structure for activities. The involvement of parents and the opportunity to contribute to supporting their children's home learning played a major role.
\end{abstract}

Keywords: COVID-19, inequality, remote learning, teacher's skills, vulnerable learners.

\section{Introduction}

Countries around the world have undergone an unprecedented change in 2020/21 due to the pandemic; a change that is likely to have a potentially far-reaching, long-term impact on children. Existing evidence indicates that countries around the Europe varied in how they adapted their education systems to online learning during COVID-19 (Mohan et al., 2020; 
Rannastu-Avalos \& Siiman, 2020; Sharp et al., 2020). While schools have made valiant efforts to continue the provision of learning for students, the success of those efforts has varied, and has often been hindered by limited access to resources available in the homes and lack of parental support. The changes have enforced existing social inequalities as not all families have had sufficient skills, resources, time or health to assist children with remote learning. The level or resources in the schools and teachers information and communication technology (ICT) skills also vary. The COVID-19 crisis affected the schools in many ways, depending on students socio-economic background, school type and size, language of instruction etc., however pandemic has not necessarily created new inequalities, but has certainly made existing ones more recognisable (Sahlberg, 2020). Closing the schools affected 1.5 billion students globally (UNESCO, 2020) and raised a question - how vulnerable student groups are socially and educationally impacted by remote learning.

Social and economic conditions where students live and learn are social determinants of health and educational disadvantage. Young people who have been exposed to more disadvantage than their peers, are described in terms of vulnerability. Social vulnerability refers to "resilience of communities when confronted be external stressors such as complex and cascading effects from COVID-19 disruption" (Drane et al., 2020, p. 3).

Based on previous research, children's access to resources is the key factor to drive educational inequalities in general and expected to do so particularly at the time of lockdown. One of the key factors for learning success during periods of remote learning is parental support. During normal times parents with higher socio-economic status tend to be more involved in activities that positively influence children's learning outcomes. It is also important to mention, that during pandemic, higher educated parents were more likely to be working from home, and therefore more able to balance work commitments and children's homeschooling needs. In contrast, lower educated parents were either more likely to continue working at their workplace or in some cases to lose their jobs (Educational inequalities in Europe, 2020). Children who lack support were already lower performers before the crisis but in situation of COVID-19, educational inequality has been increased because of family related factors. In addition to family related factors, there are important school related factors, including teachers' skills and available resources. According to TALIS (OECD, 2019) 74\% Estonian teachers mentioned "development of ICT skills" as a most crucial training topic but only half of teachers in Estonia who have graduated university in the last five years feel prepared to use ICT tools to teach their subject and are able to support their students through digital technology. Obviously, in schools where digital learning platforms and tools were used 
before COVID-19 and teachers were prepared to cope with distance learning (technological and pedagogical) and work-related stress, the transition to remote learning was easier (Lepp et al., 2020).

The results of studies related to school closure due COVID-19 in many countries demonstrate a dramatic increase of teachers workload. According to Kaden (2020), online education can support learning only in case if it ia carefully designed and individualized to not deepen inequality and social divides. In the same time "The forced move to online learning may have been the catalyst to create a new, more effective hybrid model of educating students in the future.... and virtual learning cannot be seen as a cheap fix for the ongoing financial crisis in funding education" (Kaden, 2020, p. 1).

Despite the fact that Estonia has built an advanced digital society long before pandemic, crisis very clearly affected our schools. Even the online teaching and learning tools, including electronic textbooks were already in use, the schools had to address many challenges. This study is focusing on first lockdown period (March, 16 - May, 18 2020) and exit since mid-May when students were able to go to school in small groups. In Estonia it was mainly arranged to help the students who had not participated in remote learning during the lockdown period.

\section{Method}

The aim of this article is to explore how Estonian teachers have experienced the teaching and learning remotely during the first lockdown period in 2020 and what are the possible consequences for vulnerable student' groups.

The study explores the following questions:

1) What digital sources were available for students to support learning based on teachers' explanations?

2) How teachers coped with remote learning of socially and educationally disadvantaged students and what challenges were faced?

The paper draws on a qualitative method, based on interviews with teachers $(n=20)$ in 10 case study schools. The case study schools were selected to represent dimensions of variation in school composition and organisation on the basis of criteria: rural/urban area, language of instruction, variety of student population (socio-economic background, students with special needs). The participants consisted of 16 female and 4 male basic school teachers, representing disciplines: Estonian langugage, foreign language, math and science, art and technology. Respondents experience varied from two to fifteen years of experience in teacher position.

Data were collected from individual in-depth interviews based of predefined questions. The interview questions were formulated based 
on Beaunoyer et al. (2020) theory on impacts of the COVID-19 crisis on digital inequalities. According to them, "beside purely quantitative largescale investigations, there is a critical need to consider and document individuals' experiences of the crisis" (Beaunoyer et al., 2020, p. 7). The semi-structured interview questions included open-ended questions about digital sources available for remote learning and how vulnerable student learning was perceived, including encountered challenges. The respondents were informed about aim and content of the study and were asked to give permission for anonymous use of the research data.

Recorded interviews were transcribed using automatic transcription programme of Tallinn Technical University. Transcripts were uploaded into a QCAmap to facilitate organization and analysis (QCAmap). The thematic analysis method was chosen for analysing the data. In order to maximise the reliability of the study, re-encoding and researcher triangulation was used. For reporting, codes were combined into the following categories to focus on answering the research questions: (a) digital sources, (b) coping and challenges, (c) availability of support services.

\section{Results}

\section{Sources available to support distance learning}

Teachers described variety of available web based tools: e-School and Studium; portal for digital learning materials: E-Schoolbag and Opiq, FB groups. During the distance learning teachers saw a considerable increase in the use of mentioned platforms and tools. In particular, emphasis was placed on experiential counseling and sharing information:

As a teacher I was really happy about FB group Homeschooling using techology. They share advice and experience on how to conduct learning using technology. It also helps students and parents to learn and to teach (Secondary teacher in urban school).

The teachers highlighted particular value of the SEN website (Innove, s.a.) which offers study materials suitable for pupils who study under the simplified curriculum or for students with coping difficulties. In "regular times" teachers used to have those materials for adaptive teaching, now their necessity became apparent for facilitating remote learning. Teacher of SEN students reported:

Practically overnight I started to adapt these materials for distance learn-

ing. I can't imagine my work as a teacher of SEN students without such a repository (Basic school teacher).

In addition, regional services providing counselling to pupils with special education needs (SEN) promptly responded to remote learning. Network of 
Pathfinder Centres switched to remote services, including phone or video counselling for families.

Teachers in multilingual schools (mainly in Russian-speaking regions) perceived the complexity of language learning and the decline in students' motivation. Widely popular immersion programs had to find new and an effective ways to conduct bilingual education. Teachers emphasized importance of ongoing support for language learning and vocabulary building, therefore they also found help from the Innove (s.a.) website. The popularity of language learning e-platforms increased significantly, but at the same time it required independent and self-directed learning skills, which proved to be a limitation for vulnerable target groups.

From the choice of online environments teachers appreciated highly "Head Matters" - the online consultation platform to promote mental health and facilitate access to different services and early intervention (Peaasi, s. a.). As the team consists of qualified mental health specialists, youth workers and ICT specialists, they have developed interactive information materials and training tools on mental health and disorders. User friendly and engaging website with videos and animations was perfect tool not only for youngster but also for teachers and parents. During the lockdown period the online consulting service played a vital role.

\section{Coping with remote learning of disadvantaged students and faced challenges \\ Coping and challenges}

Respondents highlighted that learning cap increased during lockdown period. Study time reduced by about half: low-achievers reduced learning time significantly more than high-achievers. During the pandemic, parents with higher education were more able to balance the work and home responsibilities to support children homeschooling. Lower educated parents as a rule worked on the "front line" which led to gaps in learning and declining of social skills. Issues affected SEN pupils engagement like the shock to everyday routine and wellbeing were mentioned. As remote learning was not suitable for some students with SEN, alternative solutions had to be found. Pupils with SEN faced behaviour problems and also fear of communication via the screen:

I have a student who doesn't even talk to his family members via Skype...

I only got in touch with him late at night when his mother came home from work (Primary teacher in urban school)

Teachers also mentioned that the lack of technological means will create stratification, not everyone can study at home. Lack of resources (computers, laptops, a high-speed internet connection, quiet study room, parents 
involvement and limited opportunities to provide homeschooling support) were indicated as barriers to remote learning:

My student, who is from a large family of 10, was able to use the computer a maximum of once a week when the older siblings had done their school work (Primary teacher in rural school)

There were difficulties in organizing remote learning for (Russian speaking) immersion students in a situation where the language skills of both children and parents were not sufficient to study independently and support learning.

Some interviewees described cases where the shift to remote learning was a positive experience for both - students and parents. Remote learning was preferred by students who have experienced anxiety around school. In those cases school refusers with special education needs and mental health issues reengaged after the shift to remote learning.

\section{Availability of support services}

Although online consulting services were in place, there was interruption of some specific support services for children with SEN:

Many support workers temporarily stopped working because they were at risk due to their age (Special education teacher in urban school)

Therapies that required physical contact were also discontinued. At the same time new support measures emerged. For example, teacher education universities provided ad hoc consultation to teachers and other school staff members. Teacher students took the role of assistant teacher in many schools where help was required.

\section{Discussion}

Literature on educational inequalities widely acknowledges that differences in home environments and parental support are important for explaining lower school performance of disadvantaged students (Educational inequalities 2019, p. 1). For many students with special educational needs the impact of lockdown was strongly negative, cutting them off from vital school-based supports while also bringing new pressures to bear on them (Mohan et al., 2020, p.69). Students from families in which the parents were frontline workers were in a more vulnerable position in terms of home support as they often had no parental assistance (Mägi, 2021). In Estonia more than a fifth (22\%) of parents admitted that their children needed constant assistance from parents (Lauristin et al., 2020).

Results of this study revealed that teachers faced many challanges in coping with remote learning of disadvantaged students. In situation of COVID-19 educational inequality has been increased because of family 
related factors - unequal conditions and availability to parental assistance. Issues affected SEN pupils engagement like loss of daily routine and wellbeing were mentioned. In some cases the shift to remote learning impacted negatively on disadvantaged students' social- and selfregulation skills.

Estonia had key tools and sources available to support remote learning already before pandemic. During the remote learning teachers saw a considerable increase in the use of platforms and tools like e-School, Studium; E-Schoolbag, Opiq, etc. Results from the Children's Advisory Panel's survey of 10-18 year-olds indicated that students in Estonia had "an above-average level of satisfaction with home learning compared to the other seven countries participating in the survey. Estonia also had the highest share of students who reported that during school closures, they had good access to the internet (73\%) and to school systems (69\%)" (OECD, 2020, p. 4). In the same time, based on survey, done in Estonia in summer 2020, there were $10 \%$ of students who did not cope at all during the first remote learning period (as teachers used to say: "disappeared from the picture"). This is a significant number of students who may be at risk of dropping out in the future (Lauristin et al., 2020).

As teachers faced insufficient knowledge and skills how to support learners with disadvantaged background, more attention should be paid to specific methods, how to adapt learning materials, support alternative learning options and sustain engagement in remote learning of different vulnerable groups. This applies to learners with special needs but further targeted supports are required for Russian-speaking and immigrant students in order to ensure equity for all learners groups.

The results of this study are in line with research of Beilmann et al. (2020, p. 29) that existing socioeconomic inequalities may be reinforced in time of pandemic and "socioeconomic inequalities need extra attention in analysing teaching practices and learning outcomes in the field of digital skills development." The lesson learned from the first wave of the COVID-19 is that "predictability and stability in digital learning environments would help to spare all parties (teachers, students and families) from unnecessary confusion, communicative efforts and loss of time of" (Beilmann et al., 2020). The results can be used in teacher education, integrating teachers' digital skills with different subjects. The results are also applicable in schools and parental associations, forming partnerships to minimize social inequalities. 


\section{References}

Beaunoyer, E., Dupere, S., \& Guitton, M. J. (2020). COVID-19 and digital inequalities: Reciprocal impacts and mitigation strategies. Computers in Human Behaviour, 111. https://doi.org/10.1016/j.chb.2020.106424

Beilmann, M., Opermann, S., Kalmus, V., Donoso, V., Retzmann, N., \& d'Haenens, L. (2020). Home-school communication on children's digital skills development: Based on interviews with experts from the education sector. KU Leuven, Leuven: ySKILLS.

Drane, C., Vernon, L., \& Shea, O. S. (2020). Vulnerable learners in the age of COVID-19: a scoping review. The Australian Educational Researcher. https://doi.org/10.1007/ s13384-020-00409-5

Educational inequalities in Europe and physical school closures during COVID-19. Fairness Policy Briefs Series, 04/2020. Retrieved from: https://ec.europa.eu/jrc/sites/ jrcsh/files/fairness_pb2020_wave04_covid_education_jrc_i1_19jun2020.pdf

Innove, s. a. Hariduslike erivajadustega õpilaste õppevara arendamine (Development of study materials for students with special educational needs, in Estonian). Retrieved from: https:// hev.edu.ee/

Kaden, U. (2000). COVID-19 School Closure-Related Changes to the Professional Life of a K-12 Teacher. Education Sciences, 10, 165. https://doi:10.3390/educsci10060165

Lauristin, M., Loogma, K., Erss, M., Tuubel-Vernik, E.-M., \& E.-S. Sarv. (2020). Õpilaste, õpetajate ja lapsevanemate toimetulek koroonakriisi aegses kaugõppes (Students, teachers and parents coping with distance learning during the COVID crisis, in Estonian). Eesti Haridusfoorum.

Lepp, L., Aaviku, T., Leijen. Ä., Pedaste, M., \& Saks, K. (2021). Teaching during COVID-19: The Decisions Made in Teaching. Educ. Sci, 11, 47. https://doi.org/10.3390/ educsci11020047

Mohan, G., McCoy, S., Carroll, E., Mihut, G., Lyons, S., \& Mac Domhnaill, C. (2020). Learning for all? Second-level education in Ireland due COVID-19. ESRI Survey and Statistical Report Series, No 92. https://doi.org/10.26504/sustat92.pdf

Mägi, E. (2021). Country report on the impact of COVID-19 lockdown on schooling in primary and secondary education: Estonia. In: What did we learn from schooling practices during the COVID-19 lockdown? Insights from five EU countries. European Commission: JRC Science for Policy Report.

OECD (2019). TALIS 2018 Results (Volume I). Teachers and School Leaders as Lifelong Learners. Retrieved from: https://www.oecd.org/education/talis/talis-2018-results-volume-i1 dObc92a-en.htm

OECD (2020). Education Policy Outlook. Estonia. Retrieved from: https://www.oecd.org/ education/policy-outlook/country-profile-Estonia-2020.pdf

Peaasi, s.a. Retrieved from https://peaasi.ee/en/

QCAmap, s.a. A software for Qualitative Content Analysis. Retrieved from: https://www. qcamap.org/ui/home

Rannastu-Avalos M., \& Siiman L.A. (2020). Challenges for Distance Learning and Online Collaboration in the Time of COVID-19: Interviews with Science Teachers. In: Nolte A., Alvarez C., Hishiyama R., Chounta IA., Rodríguez-Triana M., Inoue T. (Eds) Collaboration Technologies and Social Computing. CollabTech 2020. Lecture Notes in Computer Science (pp. 128-142). Springer, Cham. https://doi. org/10.1007/978-3-030-58157-2_9 
Sahlberg, P. (2020). Will the pandemic change schools? Journal of Professional Capital and Community, 5, 3/4. https://doi.org/10.1108/JPCC-05-2020-0026

Sharp, C., Nelson, J., Lucas, M., Julius, J., McCrone, T., \& Sims, D. (2020). Schools Responses to COVID-19. The challenges facing schools and pupils in September 2020. National Foundation for Educational Research.

UNESCO (2020). COVID-10 educational disruption and response. Retrieved from: https:// en.unesco.org/news/COVID-19-educational-disruption-and-response 